\title{
Development of High Power Density Inverter for Automotive Appl ications
}

\author{
Byong Jo Hyon,", Yong-Su Noh, Joon Sung Park, Jin-Hong Kim, Jun-Hyuk Choi \\ ${ }^{*}$ Korea Electronics Technology Institute, 388 songnaedaero, Wonmi-gu, Bucheon-si, 14502, Korea \\ *Corresponding Author: bjhyon@keti.re.kr
}

\begin{abstract}
This paper presents the development of a high power density inverter system for automotive applications. For energy issues, the power conversion system and module in high power system including vehicles, have been researched. Recently, large-capacity and high output of electric motors, inverters, and batteries have become many issues. Because the internal space of the car is limited, it is required to increases the output density to increase the output performance while reducing the size. This has been studied in connection with the cooling structure of the vehicle.

In this paper, the design of high power density inverter was presented and experimental results was verified using prototype inverter for vehicle.
\end{abstract}

Keywords: Inverter, Power density, EV.

\section{Introduction}

The interest in electric vehicles has increased beyond commercialization. Beyond the early stages of simply driving with electricity, it have reached a stage of thinking about optimization in efficiency and cost. To improve efficiency and reduce cost, maintenance problem, many researchers developed topology, materials and control algorithm [1]. Actually, the components of inverter have been developed. Power module has been smaller and increased in voltage and current ratings. The cooling methods and structure also has been developed. To combine all of these points, it is followed the improvement of performance and optimization of inverter structure and volume.[2]

In this paper, the development of the high power density traction inverter system for high power electric vehicles was presented. Through the experimental results, validity and quality of the reported designs are verified.

\section{Configuration of Inverter system}

Fig.1 shows the configuration of high power density inverter systems.

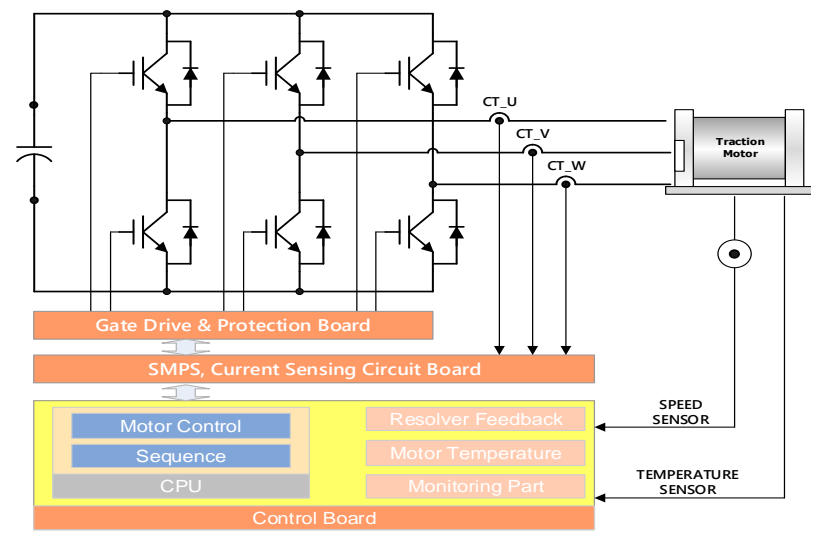

Fig. 1. Configuration of Inverter System

\subsection{Design of high power density inverter for automotive applications}

The configuration of high power density inverter as shown in fig. 1 consist of control part, power part and gate drive part. The gate drive part inject gate signals to power module. There are many topologies and the boot strap type of gate drive has been adopted in this inverter. The source of gate drive IC has single power source and is generated by flyback type converter. The power part has capacitor bank connected dc busbar, which used in input of inverter. The capacitor has ratings $100 \mathrm{uF}$ and $450 \mathrm{~V}$ and input voltage of inverter has varied from $270 \mathrm{~V}$ to $360 \mathrm{~V}$. The control part of inverter has generated switching pattern from sensing current, voltages and motor position. The microprocessors generates torque reference and switching patterns using feedback 
values from sensing parameters. The power source for control part consist of fly back converter and boost converter.
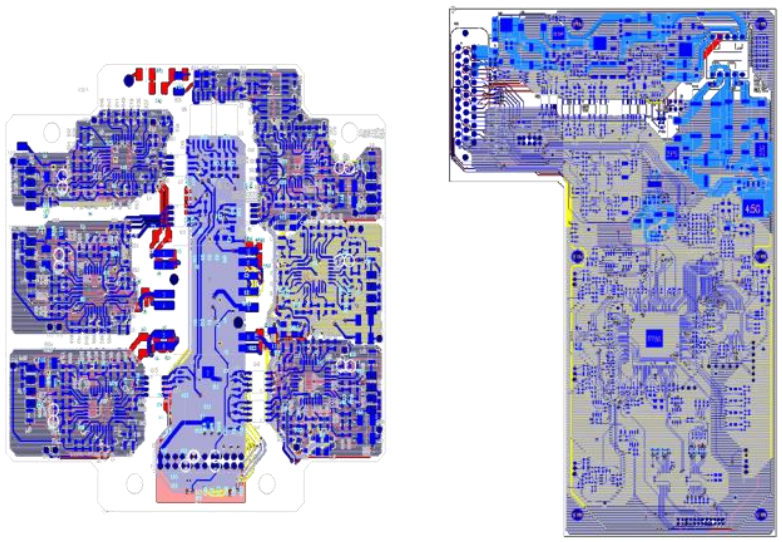

Fig. 2 PCB design of inverter

In order to complement the cooling structure and reduce the volume, we designed the case and mechanism considering the arrangement of the busbar and major components. The figure below shows the assembly of inverter case, bus bar and connector.
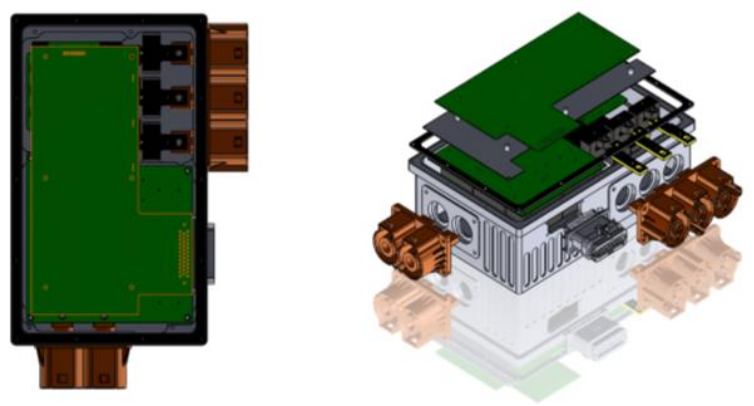

Fig. 3 Assembly drawing of inverter

\subsection{Control of inverter systems[3]-[5]}

Fig.4 shows control block diagram of inverter for electric vehicle. The control block of inverter consist of torque controller, current controller, PWM generator and dq transformation block. The torque controller based on current controller. The torque controller received torque command as input and generated current reference using by premade current look up table. The current control based on PI (proportional integration) control. The controlled current transformed from dq transformation. So, this could control ac pmsm like dc machines. The current controller input is the difference between the current command and the feedback current. The gain of current controller depended on motor parameter such as inductances and resistance. The dq

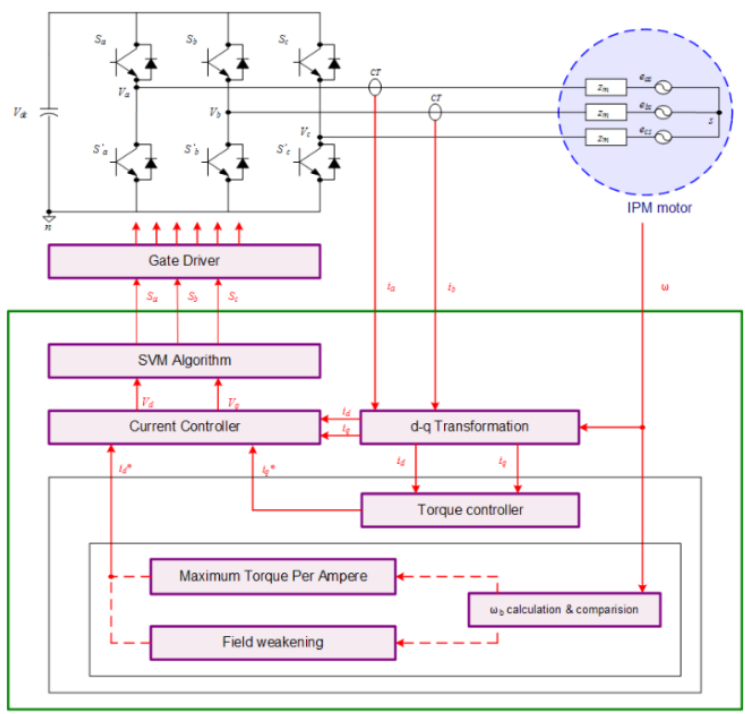

Fig. 4 Control Block diagram

transformation block achieve transformation of 3phase currents to $\mathrm{dq}$ synchronous currents. At this point, the measured motor electrical position was required. The motor position is measured by resolver. The output of current controller is voltage reference used to generate PWM. The PWM generating block based on space vector PWM methods. The generating PWM adopted power module and it achieve motor action. In low speed region, the MTPA (maximum torque per ampere) control was dominant. In high speed region, the field weakening control was adopted to compensate voltage margin.

The protection of inverter has been adopted. The over voltage of dc link voltage, the over current of 3 phase current by software and hardware, the arm short of power module and resolver fault detection were adopted in control sequence.

After confirming the protection operation, the control algorithm examined the whole hardware operation by using the induction machine. After that, it is designed adc(analog to digital) operation of measuring current, voltage, resolver and so on. Based on this, the inverter software was developed through the configuration of the current controller through the load operation.

The motor control by inverter based on motor voltage equations as shown below. The dynamics of interior permanent magnet synchronous motor in steady state are represented as

$$
\begin{aligned}
& v_{d}^{e}=r i_{d}^{e}-\omega L_{q} i_{q}^{e} \\
& v_{q}^{e}=r i_{d}^{e}+\omega L_{d} i_{d}^{e}+\omega \psi_{m}
\end{aligned}
$$

To control motor in high speed region, the current reference generated by field weakening control method. [5] 
The current reference is represented as

$$
\begin{aligned}
& i_{d}^{e *}=\frac{1}{\left(\xi^{2}-1\right)}\left(\frac{\psi_{m}}{L_{d}}-\sqrt{\xi^{2} \frac{\psi_{m}{ }^{2}}{L_{d}{ }^{2}}+\left(\xi^{2}-1\right)\left(\xi^{2} I^{2}-\frac{V^{2}}{\omega^{2} L_{d}{ }^{2}}\right)}\right) \\
& i_{q}^{e *}=\sqrt{I S^{2}-i_{d}^{e * 2}}
\end{aligned}
$$

Equation (2) shows theoretical current reference and this depends on parameter such as inductance and resistance. The inductance changes by currents, this requires iterative calculation and it is very complex. So, the look up table is used to generate current reference in practically. This method finds the current combination with the maximum torque, changing the current angle for a given current magnitude. Fig. 5 shows the block diagram of current reference generation.

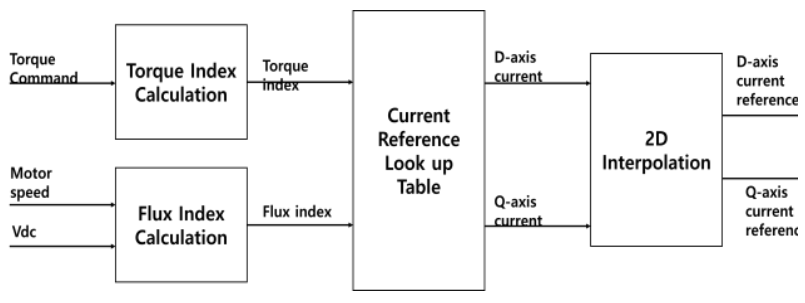

Fig. 5 Current reference generating block

\section{Experimental Results}

Fig.6 shows the developed inverter prototype. As mentioned in previous sections, the inverter consist of the control, power and gate drive part. Also, there are various
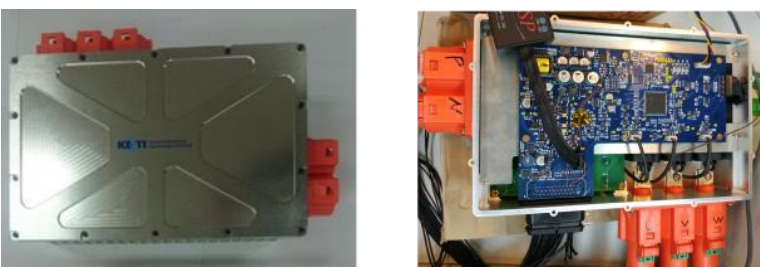

Fig. 6 Prototype of inverter

kind of sensors, busbar and connectors.

\subsection{Experimental Setup}

Fig. 7 shown the experimental setup. The test motor connected to load motor in dynamo system and torque measured by torque sensor. The load side motor driven by load universal inverter and driven speed control mode. The target motor driven by developed inverter prototype and test mode was torque control mode. In order to evaluate the performance of the target motor, experiments for performance test were performed up to $9,000 \mathrm{rpm}$ in 1,000 rpm increments up to $255 \mathrm{Nm}$ in $35 \mathrm{Nm}$ incremented to load motor in dynamo system. The motor speed, torque, 3 phase current, voltages, dc link voltage and dc link current were measured in power analyzer, WT3000, Yokogawa. The power analyzer measured parameter and calculated motor power, inverter power, input dc power and efficiency of motor, inverter and overall system. In this experiments, the

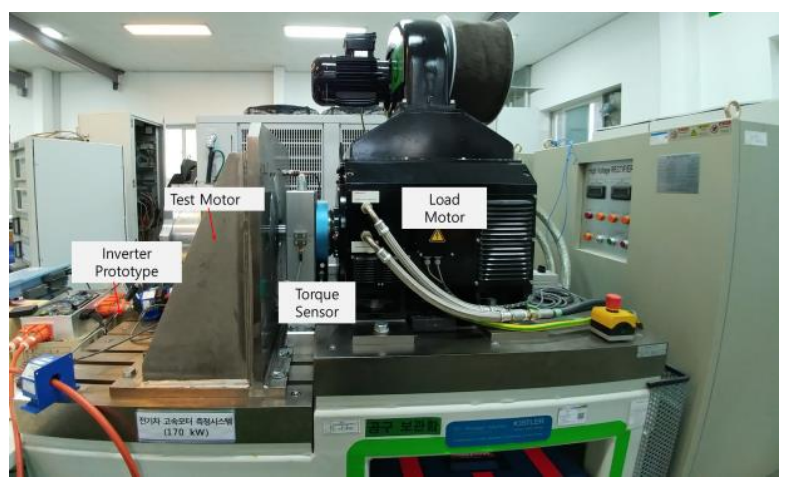

Fig. 7 Experimental Setup

inverter and motor performance were verified by efficiency.

\subsection{Experimental Results}

Fig. 8 shown the efficiency of the target motor. The motor exhibited a maximum efficiency distribution at about $140 \mathrm{Nm}$ between $3000 \mathrm{rpm}$ and $5000 \mathrm{rpm}$ and was measured at a maximum efficiency of $97.2 \%$ at $5000 \mathrm{rpm}$ and $140 \mathrm{Nm}$. Fig. 9 shows the efficiency of inverter. The inverter was measured at a maximum efficiency of $98.2 \%$ at $8000 \mathrm{rpm}$ and $70 \mathrm{Nm}$. Fig.10 shows the system efficiency map. The system efficiency map calculated by motor and inverter input output power and the maximum efficiency was measured at

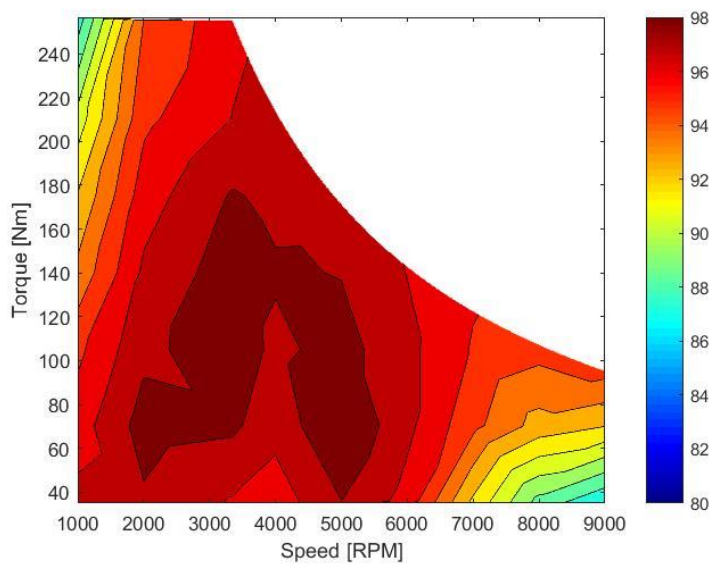

Fig. 8 Efficiency of target motor 


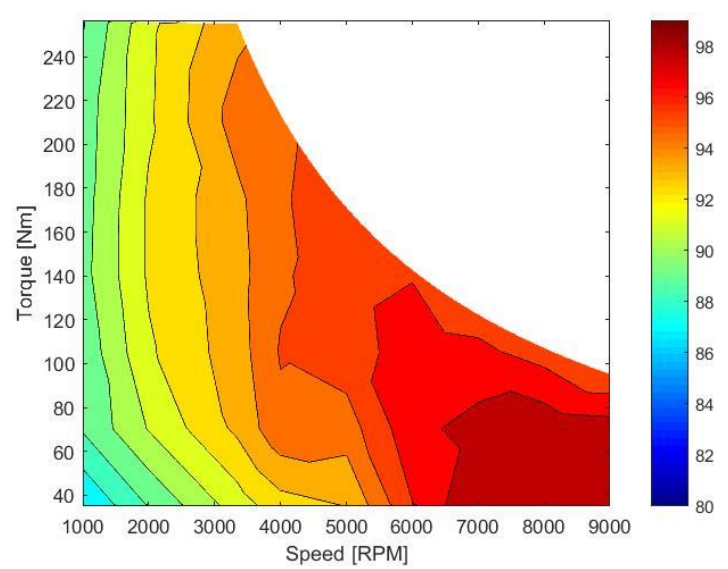

Fig. 9 Efficiency of inverter

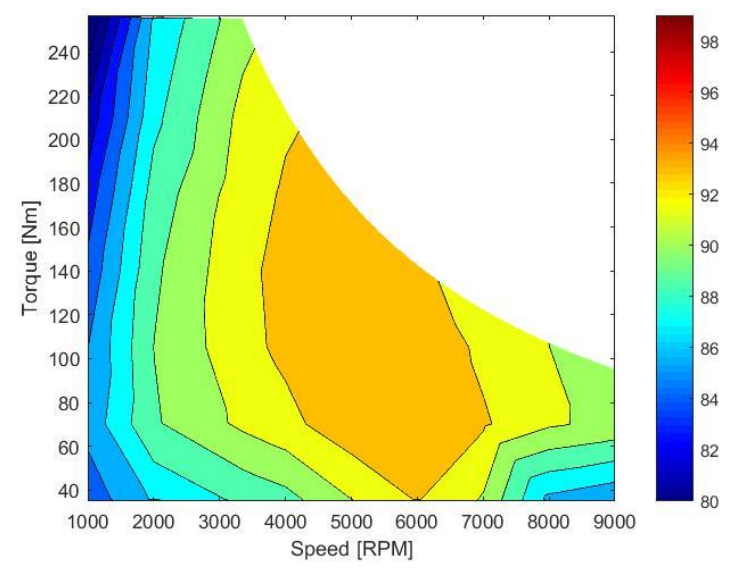

Fig. 10 Efficiency of overall system

93.3\% at about 5,000 rpm and $105 \mathrm{Nm}$. The volume of inverter is $6.4 \mathrm{~L}$ and maximum output inverter power is $93.27 \mathrm{~kW}$. So, the power density of inverter measured 14.4 $\mathrm{kVA} / \mathrm{L}$

\section{Conclusions}

This paper presents development of the high power inverter system for high power electric vehicles. For considering cooling jacket, the size of heat sink and system volume could be reduced. In order to develop new typed cooling method, 3D modeling of heat sink and switched mode power supply (SMPS) of controller were redesigned. Through the experimental results, validity and quality of the reported designs are verified

\section{Acknowledgment}

This work was supported by Korea Evaluation Institute of
Industrial Technology (KEIT) through the Development of Electric Vehicle Drive System based on High Efficiency

Cooling System. (No.10063006)

\section{References}

(1) M. Zeraoulia, M. E. H. Benbouzid, and D.Diallo, "Electric Motor Drive Selection Issues for HEV Propulsion Systems: A Comparative Study,” IEEE Trans. on Vehicular Technology 55(6), 2006, pp.1756-1764

(2) Y.murakami, Y.Tajima, S. Tanimoto, Air-cooled full$\mathrm{SiC}$ high power density inverter unit, Proceedings of IEEE EV27, 2013, pp 1-4.

(3) T.J.E. Miller, and Hendershot, Design of Brushless Permanent-Magnet Motors, Magna Physics publishing and Clarendon Press, Oxford, 1994

(4) J.S. Park, and Kwanghee Nam, "Dual inverter strategy for high speed operation of HEV permanent magnet synchronous motor," Proceedings of IEEE IAS Annual Meeting Conference, 2006, pp.488-494

(5) Kwanghee Nam, AC Motor Control and Electric Vehicle Applications, CRC Press, 2010. 